\title{
3D Animation and Virtual Reality Integrated Cognitive Computing for Teaching and Learning in Higher Education
}

\author{
Abhishek Kumar ${ }^{\text {a,1 }}$, Rini Dey ${ }^{\text {a }}$, G. Madhukar Rao ${ }^{\text {b }}$, Saravanan Pitchai ${ }^{\text {c }}$, K. \\ Vengatesan ${ }^{\mathrm{d}}$, V. D Ambeth Kumar ${ }^{\mathrm{e}}$ \\ ${ }^{a}$ School of Computer Science and IT, JAIN (Deemed to be University), Bangalore, India \\ ${ }^{b}$ Department of Computer Science \& Engineering, Koneru Laksmaiah Education Foundation, \\ Hyderabad, India \\ ${ }^{c}$ Faculty of Engineering and Technology, SRM Institute of Science and Technology, Kattankulathur, \\ India \\ ${ }^{d}$ Department of Computer Engineering, Sanjivani College of Engineering, Kopargaon, India \\ ${ }^{e}$ Department of Computer Science \& Engineering, Panimalar Engineering College, Anna University,
} Chennai, India

\begin{abstract}
This paper proposes the and justify how we can enhance the quality of medical education through immersive learning and AI (Artificial Intelligence) use in education. A Multimodal Approach for Immersive Teaching and learning through Animation, AR (Augmented Reality) \& VR (Virtual Reality) is aimed at providing specifically medical students with knowledge, skills, and understanding. It is important to understand the current challenge involved in medical education. This paper reports the findings of a novel study on the technology enable teaching with Animation, AR and VR by and MR impact. A case study was conducted involving 521 participants from different states of India. The data was analyzed by their feedback after using this Virtual reality-based teaching procedure in classroom. Recommendations from this paper that are expected to effectively improving the quality of medical education in faster way.
\end{abstract}

Keywords. 3D Animation, Cognitive Computing, AI, Virtual Reality

\section{Introduction}

At present, Innovation and technology are playing an essential role in the enhancement of the standard of education and students' learning outcome. Creativity and Innovation in education have improved a lot recently. One of the rising advancements that have started more prominent enthusiasm for educational technology is Virtual Reality, Augmented Reality, and Mixed Reality. Future educators must have a satisfactory result when implementing this immersive technology in education. Since this is a matter which concerns the current enthusiasm on a universal level to reduce use the technology in education [2-4]. "Learning will be significantly changed by AI," says UNESCO Director-General Audrey Azulay.

\footnotetext{
${ }^{1}$ Abhishek Kumar, School of Computer Science and IT, JAIN (Deemed to be University), Bangalore Email: abhishek.maacindia@gmail.com.
} 
"Showing apparatuses, methods for learning, access to information, and instructor preparing will be upset." [5] The Fourth Industrial Revolution serves as a comprehensive unit for terminologies of 3D - Printing, Artificial Intelligence, BIG data, and the Internet of things, in the education sector. For partnerships, it implies reexamining procedures and auto-cannibalization of plans of action. Its impacts on work and business are a gauge to be mind-boggling, conceivably elevating disparity by diminishing interest for low degrees of abilities. Utilizing savvy AI-fueled frameworks can enormously trigger the fruitfulness of innumerable instructive foundations, reduce their operative costs and provide noteworthy perceivability into payments and expenses. Implementing these technologies in education improves the general responsiveness of students and the excellent performance result."[6].

\section{AR, VR AND MR In Higher Education}

Virtual Reality is starting to change the classroom from 2017 worldwide. Harder, Better, Faster, Stronger (HBFS) are the four key words that can most efficiently depict the potential effect that the usage of VR and AR can make in the framework of instructions. Innovations are required within the training framework to remain relevant in the ever-changing world [7-8].

Virtual and Augmented Reality is the following legitimate advance in the development of the Education System. This Reality of training will be significantly affected by the presentation of new AI-based advances, and that is the Virtual Reality-based real-time learning experience [9-12]. Higher Education has seen an upsurge in the application of Artificial Intelligence (AI) with huge consideration over the recent past. In the 2018 Horizon report the undenied progression of Artificial Intelligence and versatile learning have been highlighted as noteworthy advancement, with an opportunity to attain appropriation within 2 to 3 years. In conformity with the report, experts have envisioned AI to scale by $43 \%$ in training sector between 2018-2022, although the 2019 Horizon report Higher education edition anticipated that AI applications associated with instructional learning would sizeable become rather crucial than this.

Education, as a summary, tremendously affects our entire world and is one of the establishments of the human turn of events. Expanded utilization of artificial intelligence in education without a doubt carries immense potential for improving education and instructing, yet are these enhancements starting to make a superior network and a superior world? School education that squeezing needs to change under fast improvements in AI strives on post-mandatory educational developments, as well [13-14]. Business AI mastery through advanced degree and request is one of the significant methodologies utilized by governments to impart their various expertise holes. In the endeavor to expand their various capacities in AI and transform into pioneers in this field, a few countries are attempting to make callings in AI research and learn additionally engaging.

\section{Future of AI Enable Education}

The fourth industrial revolution in education has operationalized the Education 4.0 framework that validates the transformation in education through technological Innovation. As indicated by forecasts from lexalytics report, "Artificial intelligence in 


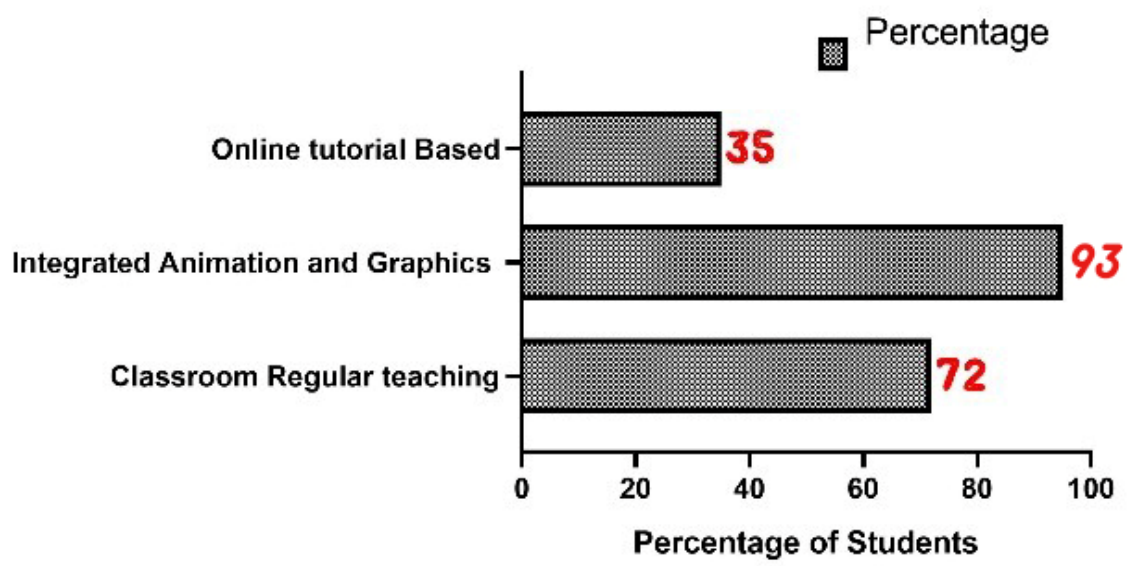

Figure 1. Student preference percent for technology-integrated learning

education will detonate throughout the following five years and is relied upon to arrive at worldwide consumption of $\$ 6$ by 2025 . [1]

By application, the market is divided into K-12, advanced education, and professional preparation. The advanced education section is required to create a more substantial income share in the market during the conjecture time frame. Virtual Reality offers consistent learning chances to the understudies. Raising support, understudy enrolment, vivid learning is a portion of the significant utilization of VR in advanced education.

Advanced education is relied upon to be the primary use of Virtual Reality in the education division. As of advanced media has made many open doors regarding the entrance to the active substance. Test learning, dominance-based learning, and customized learning are the most significant suitable advantages of VR in the education business. For Online Employee Training, there is no lack of stages and innovations. One of the approaches to connect with and train individuals could be augmented Reality (AR) and Virtual Reality (VR). Nowadays, Organizations have been utilizing VR for worker preparation. Walmart is accustomed to it to prepare workers for the fever Black Friday shopping season (they successfully made the scariest awfulness round ever - merely joking). Walmart additionally applied it to train its workers to stock retires all the more proficiently.

\section{Research and Analysis}

According to a recent survey by me in 2020, about AI enable learning, it was discovered that about $85 \%$ of Undergraduate and Postgraduate students in India have a preference for Animation and technology-integrated learning, as shown in Figure 1.

Student feedback at the time of Animation and VR integrated learning method for Teaching are Animation and VR is awesome in education. I could not imagine anything better than to see it presented in human life structures because the vast majority need visual articulation to get Reality. Excellent and fabulous representation to strengthen ideas. It simplifies the results to fathom. Amazing way to help instigate 
learning. I would not mind to bear an extra cost for this type of learning. Memory retention of teachings are quite high due to the visual aid of 3D Animations. In addition, the pleasure of learning this way by far transcends various other schemes. This must be made available for understudies; the sooner, the better. Arrange learning materials in a context where they appear better. Visual depiction of learning materials corresponding to various parts helps to identify the proximity of the ideas and hence is a great way of learning. Coping up with and assisting thought process and fascination. With the ease of understanding I would be able to impart exceptionally to the learning process, and ameliorate the relationship with complex and difficult themes.

The experience with VR technology was exceptional. Retention of data has unquestionably become simpler. Learning with the visual aid of models instead of the course book is much convenient. The kind of learning if made accessibility to people groups with learning abilities would definitely enhance learning.

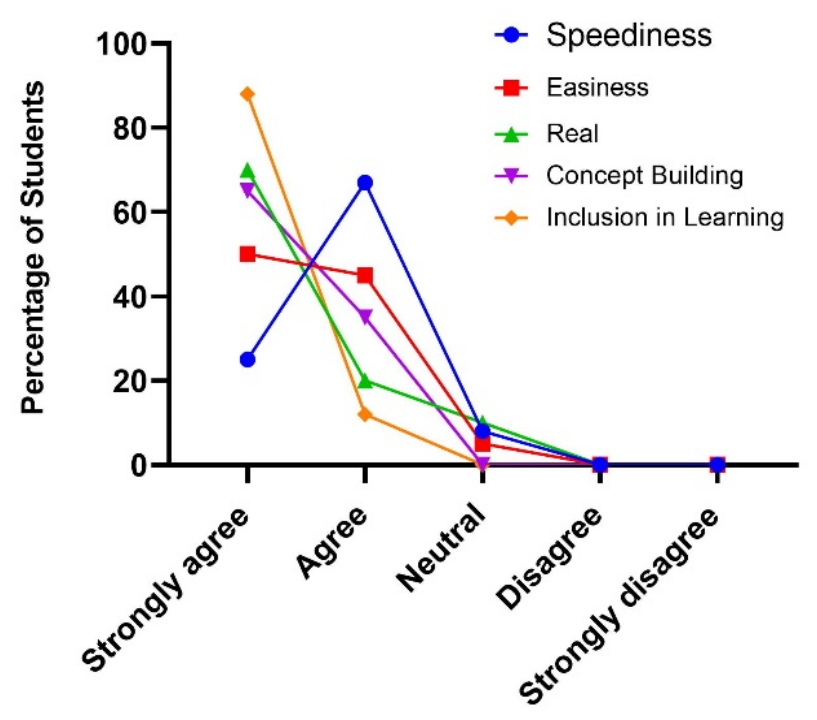

Figure 2. AR-VR learning experience

See Figure 2, Concerning VR learning experience, learning experience speed, materials were connected emphatically to this present Reality. The statistical analysis has unveiled the overflowing responses from students who strongly concur to the factors of Perception Enjoyment, Easiness, Real Concept Building Inclusion in learning.

The survey was done with google form with 521 participant pan India, and the participant responds in India AR, VR and MR are the fastest growing technology specifically in games, but in education, the use of this AI enables technology is very less. 


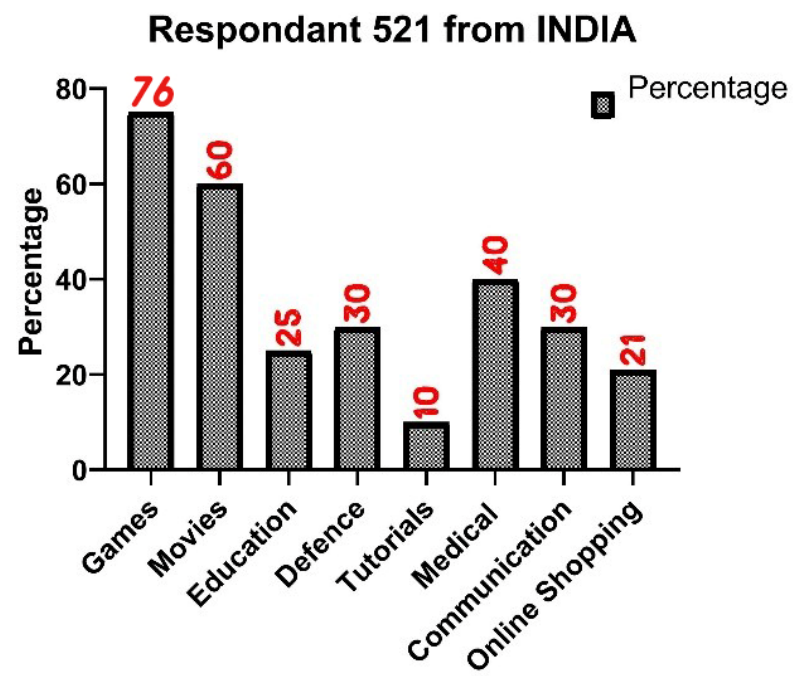

Figure 3. VR, AR, MR impact in multiple sectors

\section{Conclusion and Future discussion}

The outcome of the analysis and study clearly reveals the exceeding interest in immersive VR technologies for educational purposes. This has been indicated and verified by varieties of research domain that have implemented this technology in Teaching. The use of VR technology for higher education has been acknowledge by majority authors to be a promising learning tool. However, what is still questionable is the maturity of its use in Higher education. There is no denial of the fact that in some domains like engineering and computer science, have regularly been using specifically designed VR applications for delivering individual skills, particularly the ones that focus upon analytical, procedural and empirical knowledge. However, in several mother domains, the VR technology is still naively experimental, and is not systematically employed to best practices.

\section{References}

[1] https://www.lexalytics.com/lexablog/ai-in-education-present-future-ethics

[2] Barnes, N.; Fives, H.; Dacey, C.U.S. teachers' conceptions of the purposes of assessment. Teach. Teach. Educ. 2017, 65, 107-116.

[3] Darling-Hammond, L.; Bransford, J.D. Preparing Teachers for a Changing World: What Teachers Should Learn and Be Able to Do; Jossey-Bass: San Francisco, CA, USA, 2005.

[4] https://en.unesco.org/news/how-can-artificial-intelligence-enhance-education

[5] Potharaju, S. P., \& Sreedevi, M. (2018). A novel cluster of quarter feature selection based on symmetrical uncertainty. Gazi University Journal of Science, 31(2), 456-470.

[6] Kesavan, S., Kumar, E. S., Kumar, A., \&Vengatesan, K. (2019). An investigation on adaptive HTTP media streaming Quality-of-Experience $(\mathrm{QoE})$ and agility using cloud media services. International Journal of Computers and Applications. https://doi.org/10.1080/1206212X.2019.1575034 
[7] Kumar, A., Vengatesan, K., Rajesh, M., \& Singhal, A. (2019). Teaching literacy through animation \&amp; multimedia. International Journal of Innovative Technology and Exploring Engineering, (5), 73-76.

[8] Gurjot Singh, Stephen R. Ellis, and J. Edward Swan II. The Effect of Focal Distance, Age, and Brightness on Near-Field Augmented Reality Depth Matching. IEEE Transactions on Visualization and Computer Graphics, 26(2):1385-1398, Sep 2018. DOI: 10.1109/TVCG.2018.2869729, preprint: arXiv:1712.00088v1.

[9] A. Kumar, K. Vengatesan, A. Singhal and D. K. Verma, "3D Lighting Courseware development for 3D Motion Picture Science," 2018 International Conference on Recent Innovations in Electrical, Electronics \& Communication Engineering (ICRIEECE), 2018, pp. 2321-2323, doi: 10.1109/ICRIEECE44171.2018.9009258.

[10] A. Kumar, A. Singhal, K. Vengatesan and D. K. Verma, "Study and Research of 3D Animation Courseware Development," 2018 International Conference on Recent Innovations in Electrical, Electronics \& Communication Engineering (ICRIEECE), 2018, pp. 2514-2516, doi: 10.1109/ICRIEECE44171.2018.9008670.

[11] Nate Phillips, Kristen Massey, Mohammed Safayet Arefin, and J. Edward Swan II. Design, Assembly, Calibration, and Measurement of an Augmented Reality Haploscope. In Proceedings of PERCAR: The Fifth IEEE VR Workshop on Perceptual and Cognitive Issues in AR, 2019 IEEE Conference on Virtual Reality and 3D User Interfaces, pp. 1770-1774, Mar 2019. DOI: 10.1109/VR.2019.8798335, preprint: arXiv:1908.08532.

[12] Kumar, A., Singhal, A., \&Sheetlani, J. (2019). 3D Stereoscopy Video Production : Z-Depth Extraction and Optimized Rendering using Foundry Nuke. (1), 6658-6664. https://doi.org/10.35940/ijeat.A1926.109119

[13] J. Adam Jones, J. Edward Swan II, Gurjot Singh, Josh Franck, and Stephen R. Ellis. The Effects of Continued Exposure to Medium Field Augmented and Virtual Reality on the Perception of Egocentric Depth. In Poster Compendium, Proceedings of ACM SIGGRAPH Symposium on Applied Perception in Graphics and Visualization (APGV 2009), pp. 138, September 2009. DOI: 10.1145/ 1620993.1621032.

[14] Joseph L. Gabbard, Divya Gupta Mehra, and J. Edward Swan II. Effects of AR Display Context Switching and Focal Distance Switching on Human Performance. IEEE Transactions on Visualization and Computer Graphics, 25(6):2228-2241, May 2018. DOI: 10.1109/TVCG.2018.2832633. 